\title{
PENINGKATAN VO 2 MAX MELALUI CIRCUIT TRAINING PADA SISWA KELAS VIII.4 SMP NEGERI 4 KOTA BENGKULU
}

\author{
Memo Trisandy \\ PENJAS FKIP UNIB, e-mail: memotrisandy26@gmail.com \\ Sugiyanto \\ Universitas Bengkulu \\ Beswaldi \\ Universitas Bengkulu
}

\begin{abstract}
Abstrak
Penelitian ini bertujuan untuk mengetahui apakah dengan menggunakan circuit training dapat meningkatkan $\mathrm{VO}_{2}$ Max siswa. Penelitian ini menggunakan rancangan Penelitian Tindakan Kelas yang terdiri dari empat langkah penelitian yaitu: perencanaan, pelaksanaan, observasi, dan refleksi. Dalam pelaksanaan pembelajaran paneliti menggunakan latihan circuit training untuk meningkatkan kemampuan $\mathrm{VO}_{2}$ Max siswa. Circuit Training yang diberikan kepada siswa ditingkatkan secara bertahap. Subjek penelitian ini adalah seluruh siswa kelas VIII.4 SMP Negeri 4 Kota Bengkulu yang berjumlah 35 siswa yang tediri dari 17 orang siswa laki-laki dan 18 orang siswa perempuan. Peneliti menggunakan tekhnik pengumpulan data dengan cara melakukan observasi dan tes. Adapun tekhnik yang digunakan peneliti untuk menilai keberhasilan penelitian yakni menggunakan norma pengukuran $\mathrm{VO}_{2}$ Max Kenneth H.Cooper yang didapatkan dari Multistage Fitnes Test (MFT). Penelitian ini dilakukan dalam 2 siklus dan tes evaluasi siswa dilakukan di akhir siklus. Berdasarkan hasil penelitian yang dilakukan diperoleh hasil Pra-siklus dengan persentase 22,86\% dengan rata-rata keseluruhan $\mathrm{VO}_{2}$ Max 27.38 dan tergolong dalam kategori Kurang Sekali. Kemudian pada Siklus I dengan persentase 54,29\% dengan rata-rata keseluruhan $\mathrm{VO}_{2} \mathrm{Max} 36.34$ dan tergolong dalam kategori Sedang, dan pada Siklus II dengan persentase $80 \%$ dengan rata-rata keseluruhan $\mathrm{VO}_{2}$ Max 38.03 dan tergolong dalam kategori Sedang. Dengan demikian hasil penelitian menunjukan bahwa dengan menggunakan latihan circuit training dalam pembelajaran pendidikan jasmani dapat meningkatkan kemampuan $\mathrm{VO}_{2} \mathrm{Max}$ siswa.
\end{abstract}

Kata Kunci: Circuit Training dan Kemampuan $\mathrm{VO}_{2} \mathrm{Max}$

\begin{abstract}
This study aims to determine whether by using circuit training can increase $\mathrm{VO}_{2}$ Max of the students. This research used classroom action research was designed which research steps: planning, implementation, observation, and reflection. In the learning process the researcher used circuit training exercise to improve students $\mathrm{VO}_{2}$ Max ability. Circuit training which was given to students was gradually. The subjects of this study were all the students of VIII.4 class at SMP Negeri 4 Kota Bengkulu which was consisted of 35 students, there are 17 males
\end{abstract}


and 18 females on it. The data that used by researcher was collection techniques by making observations and tests. The techniques that used by the researcher to assess the successfull of the study is using the norms of $\mathrm{VO}_{2} \mathrm{Max}$ Kenneth H.Cooper measurement that obtained from Multistage Fitness Test (MFT). This study was conducted in two cycles and the student evaluation test was performed at the end of the cycles. Based on the results of this research had conducted percentage of $22.86 \%$ as the result of the Pre-cycle with an average of $\mathrm{VO}_{2} \mathrm{Max}$ is 27.38 and belonging to the worst category. Then Cycle I got the percentage of $54.29 \%$ with an average of $\mathrm{VO}_{2} \mathrm{Max} 36.34$ and belonging to the Medium category, and in Cycle II got the percentage of $80 \%$ with an average of $\mathrm{VO}_{2} \mathrm{Max} 38.03$ and belonging to the Medium category. From the results of this research showed that by using circuit training exercise in learning physical education can improve the ability of $\mathrm{VO}_{2}$ Max students' of VIII.4 class at SMP Negeri 4 Kota Bengkulu.

Keywords: Circuit Training and Capability $\mathrm{VO}_{2} \mathrm{Max}$

\section{PENDAHULUAN}

Kondisi pembelajaran pendidikan jasmani di SMP N 4 Kota Bengkulu sampai saat ini belum efektif meskipun telah dilakukan berbagai upaya pembenahan pada kurikulum dan melalui jalur pendidikan serta pelatihan guru. Pemahaman guru penjas masih konvensional yang menganggap bahwa pembelajaran penjas dapat dilaksanakan seadanya, sehingga pelaksanaannya relatif berpola seperti: memimpin doa, absensi, pemanasan dan menyediakan alat olahraga seperti bola dan lain-lain, kemudian dilanjutkan dengan aktivitas bermain sesuai dengan materi pembelajaran, sementara itu guru berperan mengawasi dari pinggir lapangan dan dibalik itu ternyata masih ada siswa yang tidak ikut dalam aktivitas bermain yang dikarenkan kurang antusiasnya siswa dan keterbatasan dari segi sarana serta prasarana. Dengan sistem pembelajaran yang demikian sulit rasanya untuk mencapai tingkat kebugaran jasmani yang baik terkhusus pada tingkat $\mathrm{VO}_{2}$ Max karena semakin besar $\mathrm{VO}_{2}$ Max seseorang maka semakin baik dalam menerima dan menghadapi kerja fisik (ketahanan). Oleh sebab itulah berdasarkan latar belakang diatas penulis melakukan penelitian dibidang kebugaran jasmani menggunakan latihan circuit training dengan tujuan untuk mengetahui seberapa besar "Peningkatan $\mathrm{VO}_{2}$ Max melalui Latihan Circuit Training dalam pembelajaran pendidikan jasmani pada Siswa Kelas VIII.4 SMP Negeri 4 Kota Bengkulu (Studi Penelitian Tindakan Kelas)".

Rumusan masalah dalam penelitian ini yaitu: (1) Bagaimana aktivitas guru dan siswa dalam pembelajaran pendidikan jasmani?, (2) Apakah latihan circuit training dapat memberikan peningkatan pada kapasitas $\mathrm{VO}_{2}$ Max siswa kelas VIII.4 SMP N 4 Kota Bengkulu?, (3) Seberapa besar peningkatan $\mathrm{VO}_{2}$ Max setelah diberi latihan circuit training?.

Tujuan penelitian yang ingin dicapai dari penelitian ini adalah untuk: (1) Mengetahui aktivitas guru dan siswa dalam pembelajaran pendidikan jasmani terkhusus pada peningkatan $\mathrm{VO}_{2} \mathrm{Max}$ 
melalui latihan circuit training, (2) Mengetahui tingkat $\mathrm{VO}_{2}$ Max melalui hasil latihan circuit training, (3) Mengetahui seberapa besar peningkatan $\mathrm{VO}_{2}$ Max setelah diberi latihan circuit training.

Pendidikan jasmani merupakan pendidikan yang paling unik dan paling sempurna dibandingkan dengan program studi lainnya karena melalui pendidikan jasmani seorang guru dapat mengembangkan kemampuan setiap peserta didik tidak hanya dari aspek fisik dan psikomotor semata, tetapi dapat dikembangkan pula aspek afektif, kognitif dan sosial secara bersama, Melograno dan AAHPERD dalam Giri Wiarto (2015:3).

Menurut Sajoto dalam bukunya (1988:8) mengemukakan bahwa: "kebugaran jasmani atau kondisi fisik merupakan satu kesatuan yang utuh dari komponen-komponen yang tidak dapat dipisahkan begitu saja baik dari segi peningkatan ataupun pengolahannya. Disebutkannya juga bahwa komponen kondisi fisik meliputi: kekuatan, daya tahan, kecepatan, kelenturan, kelincahan, koordinasi, keseimbangan dan ketepatan".

Kapasitas aerobik maksimal dinyatakan sebagai $\mathrm{VO}_{2}$ Max. Kapasitas aerobik pada hakikatnya menggambarkan besarnya kemampuan motorik (motoric Power) dari proses aerobik pada seorang siswa. Menurut Pate dkk, (1993:255) "kapasitas volume oksigen maksimal ( $\mathrm{VO}_{2}$ Max) adalah tempo tercepat dimana seseorang dapat menggunakan oksigen selama olahraga. Makin besar kapasitas $\mathrm{VO}_{2}$ Max akan makin besar pula kemampuannya untuk memikul beban kerja yang berat dan akan lebih cepat pulih kesegaran fisiknya sesudah kerja berat tersebut selesai".

Menurut Giri Wiarto (2015: 63), "VO2 Max adalah volume asupan oksigen maksimum. Secara umum $\mathrm{VO}_{2}$ Max adalah volume oksigen yang dibutuhkan ketika bekerja keras. Oksigen diperlukan untuk membantu dalam peroses metabolisme tubuh. metabolisme ini menghasilkan energi yang diperlukan oleh otot untuk beraktivitas". Toho Cholik dan Ali Maksum (2007: 57) menjelaskan bahwa, "Ukuran kerja cardio-respiratory-vascular sering disebut dengan volume oksigen Maximum atau disingkat dengan $\mathrm{VO}_{2}$ Max. Satuan $\mathrm{VO}_{2}$ Max adalah liter per menit atau mililiter/Kg.BB/Menit, artinya besarnya jumlah oksigen yang digunakan (dalam satuan $\mathrm{ml}$ ) setiap $\mathrm{Kg}$ berat badan permenit aktivitasnya. Semakin besar $\mathrm{VO}_{2}$ Max seseorang maka kebugaran jasmaninya semakin prima.

Kemampuan $\mathrm{VO}_{2}$ Max dipengaruhi dari berbagai faktor baik itu dari organ tubuh individu itu ataupun faktor latihan dari seseorang. Pada hakekatnya tubuh dan latihan mempunyai hubungan yang erat karena individu yang mempunyai program latihan fisik yang terolah tentu kondisi tubuhnya lebih sehat dibandingkan orang yang tidak mengolah tubuhnya. Untuk mengembangkan tingkat $\mathrm{VO}_{2}$ Max dapat dilakukan latihan-latihan yang menarik karena dengan latihan yang menarik siswa lebih cendrung semangat dalam melakukan aktivitas pembelajaran, salah satu latihan untuk kebugaran jasmani terkhusus pada pengembangan $\mathrm{VO}_{2}$ Max yaitu dapat dilakukannya latihan Circuit Training.

Yunyun Yudiana (2008:3.16) menjelaskan bahwa, "Circuit Training dikembangkan oleh Morgan dan Adamson pada tahun 1953 di University of Leeds Inggris. Sistem latihan circuit training semakin populer setelah beberapa pelatih mencoba dan mengembangkan latihan bentuk sirkuit ini dengan beberapa latihan yang dikembangkan dengan beberapa variasi latihan yang disesuaikan dengan kebutuhan pada cabang olahraga. Latihan sirkuit merupakan sistem latihan yang dapat mengembangkan secara 
serentak fitness keseluruhan dari tubuh, yaitu komponen power, daya tahan, kecepatan, fleksibilitas, dan komponen fisik lainnya".

Menurut Sajoto (1988:161), "Circuit Training atau latihan sirkuit adalah suatu program latihan terdiri dari beberapa stasiun dimana setiap stasiun dilakukan jenis latihan yang telah ditentukan. Satu sirkuit latihan dikatakan selesai apabila seseorang telah menyelesaikan latihan di semua stasiun dengan dosis yang telah ditetapkan".

\section{METODE}

Jenis penelitian yang digunakan dalam penelitian ini adalah Penelitian Tindakan Kelas (Classroom Action Research). Menurut Trianto (2011: 13), menyatakan bahwa "Penelitian Tindakan Kelas berasal dari istilah bahasa inggris Classroom Action Research, yang berarti penelitian yang dilakukan pada suatu subyek kelas untuk mengetahui akibat tindakan yang diterapkan pada suatu subyek penelitian tersebut".

Dalam Penelitian Tindakan Kelas ini subjek penelitian yang diteliti yaitu seluruh siswa kelas VIII.4 SMP Negeri 4 Kota Bengkulu, yang berjumlah 35 orang siswa dengan rincian: 17 orang siswa lakilaki dan 18 orang siswa perempuan. Penelitian ini dilakukan di Lapangan SMP Negeri 4 Kota Bengkulu dan Lapangan PGSD FKIP UNIB Jalan Cimanuk, KM 6,5 Kota Bengkulu. Waktu yang digunakan pada penelitian ini dimulai pada tanggal 2 Febuari 2017 s/d 16 maret 2017 yang terdiri dari 2 siklus yang dimana dalam satu siklus terdiri dari 3 kali pertemuan $(2$ kali tindakan kelas dan 1 kali tes kemajuan siklus).

Penelitian tindakan kelas ini dilakukan dengan menggunakan empat kegiatan pokok di dalamnya yaitu: perencanaan, melaksanakan kegiatan, pengamatan atau observasi dan melakukan refleksi pembelajaran melalui diskusi bersama dengan praktisi dan pengamat di lapangan untuk mengembangkan rencana tindakan selanjutnya, teori lewin dalam buku Trianto (2011: 29-30).

Teknik Pengumpulan Data dilakukan dengan menggunakan metode observasi dan metode praktek. Metode Observasi dilakukan langsung oleh observer (guru pamong dan teman sejawad) terhadap peroses pembelajaran dan pola pembelajaran siswa kelas VIII.4 SMP Negeri 4 Kota Bengkulu. Observasi dilakukan untuk mengidentifikasi masalah-masalah yang timbul pada saat peroses pembelajaran dan Metode Praktek dilakukan dengan cara data dalam penelitian diperoleh dari hasil Multistage Fitnes Test yang dilakukan oleh siswa kelas VIII.4 SMP Negeri 4 kota Bengkulu yang meliputi: Pra-Siklus (Tes Awal) dan Tes Siklus (Tes Kemajuan) yang dilakukan setiap akhir siklus. Pra-Siklus (test awal) bertujuan untuk mengetahui tingkat $\mathrm{VO}_{2}$ Max sebelum pemberian tindakan latihan circuit training atau sebelum ada tindakan kelas, sedangkan Tes Siklus (Tes Kemajuan) bertujuan untuk mengetahui tingkat $\mathrm{VO}_{2}$ Max setelah megikuti latihan circuit training pada siklus-siklus penelitian setelah diberikan tindakan kelas.

Instrumen adalah alat bantu yang dipilih dan digunakan oleh peneliti dalam kegiatannya mengumpulkan data kegiatan penelitian (Trianto, 2011: 54). Kualitas data sangat menentukan kualitas penelitian tindakan kelas yang diteliti. Data yang diperoleh dalam penelitian ini melalui Lembar Observasi Guru dan siswa serta Lembar Tes Praktik dengan Multistage Fitnes Test pada Pra-siklus dan setiap akhir siklus.

\section{HASIL DAN PEMBAHASAN Hasil}

Berdasarkan hasil penelitian yang telah dilakukan pada siswa kelas VIII.4 
SMP Negeri 4 Kota Bengkulu yang berjumlah 35 orang, 17 laki-laki dan 18 perempuan. Dari penelitian tersebut, diperoleh hasil yang sangat signifikan setelah diterapkannya latihan circuit training selama dua siklus yang masingmasing 3 kali pertemuan dalam 1 siklus. Latihan circuit training yang diberikan bertujuan untuk meningkatakan $\mathrm{VO}_{2} \mathrm{Max}$ siswa kelas VIII.4 SMP Negeri 4 Kota Bengkulu. Seseorang yang memiliki $\mathrm{VO}_{2}$ Max yang tinggi akan cendrung dapat lebih banyak melakukan aktivitas sebelum menjadi lelah dibandingkan orang-orang yang memiliki $\mathrm{VO}_{2}$ Max yang lebih rendah dalam melakukan aktivitas daya tahan, sehingga semakin besar $\mathrm{VO}_{2}$ Max seseorang maka semakin baik dalam menerima dan menghadapi kerja fisik (Has5n.wordpress.com).

Pada saat pra-siklus, untuk mengetahui kemampuan $\mathrm{VO}_{2}$ Max siswa peneliti menggunakan Multistage Fitnes Test (MFT). Setelah dilakukan Multistage Fitnes Test ternyata hanya $22,86 \%$ siswa yang mendapatkan nilai sedang keatas dan $77,14 \%$ dari jumlah siswa belum bisa memaksimalkan kemampuan $\mathrm{VO}_{2}$ Max mereka. Pada Pra-siklus didapatkan nilai rata-rata keseluruhan $\mathrm{VO}_{2}$ Max sebesar 27.38 sehingga berkategori Kurang Sekali. Permasalahan yang dihadapi pada saat Pra-siklus kurang antusiasnya siswa dalam mengikuti pembelajaran pendidikan jasmani dan kesehatan yang dikarenakan tingkat daya tahan siswa yang relatif masih rendah.

Pertemuan pada siklus I disajikan dalam 3 pertemuan ( 2 kali tindakan berupa latihan circuit training dan 1 kali MFT) yang dilakukan setiap jam pembelajaran pendidikan jasmani dan kesehatan di sekolah. Pada pertemuan pertama siklus I, peneliti menggunakan circuit training dengan 6 pos/stasiun latihan yang terdiri dari: Skipping, Sit-up, Shuttle Run, Push-up, Lompat Cone dan
Squat Trush. Perbandingan waktu yang digunakan pada pertemuan pertama di siklus I ini adalah 30:60 detik atau 30 detik melakukan gerakan dalam setiap pos dan 60 detik istirahat sembari mempersiapkan untuk aktivitas circuit training di pos selanjutnya.

Pada pertemuan kedua siklus I, peneliti menggunakan latihan circuit training dengan 6 pos/stasiun latihan yang terdiri dari: Passing Bola, Sit-up, Shuttle Run, Push-up, Lompat Cone dan Squat Trush. Perbandingan waktu yang digunakan pada pertemuan kedua di siklus I ini lebih ditingkatkan lagi dibandingkan pada pertemuan pertama di siklus I, yaitu dengan perbandingan 60:60 detik atau 60 detik melakukan gerakan dalam setiap pos dan 60 detik istirahat sembari mempersiapkan untuk aktivitas circuit training di pos selanjutnya. Pada pertemuan kedua siklus I ini juga peneliti menggunakan lembar observasi aktivitas guru dan siswa yang diamati oleh guru pamong pak Febridian dan teman sejawat Ade Andri Setiawan. Pada lembar observasi guru didapatkan nilai $80 \%$ untuk nilai mengajar dan $73,33 \%$ untuk nilai observasi aktivitas siswa dalam pembelajaran.

Pada pertemuan ketiga akhir dari siklus I, peneliti menggunakan Multistage Fitnes Test (MFT) untuk mengukur kemampuan $\mathrm{VO}_{2}$ Max siswa kelas VIII.4 SMP Negeri 4 Kota Bengkulu setelah diberi tindakan satu siklus. Dari Multistage Fitnes Test yang telah dilaksanakan ternyata kemampuan $\mathrm{VO}_{2}$ Max siswa mengalami peningkatan dengan rincian: Baik Sekali 0\%, Baik 20\%, Sedang 34,29\%, Kurang 37,14\% dan Kurang Sekali 8,57\%. Berdasarkan data tersebut siswa yang mendapatkan kategori sedang ke atas yaitu 54,29\% dari jumlah keseluruhan siswa kelas VIII.4 SMP Negeri 4 Kota Bengkulu dengan nilai rata-rata keseluruhan $\mathrm{VO}_{2}$ Max sebesar 36.34 
sehingga berkategori Sedang. Karena belum mencapai indikator yang diharapkan yaitu $\geq 70 \%$, maka penelitian dilanjutkan pada siklus kedua.

Pertemuan pada siklus II juga disajikan dalam 3 pertemuan $(2$ kali tindakan berupa latihan circuit training dan 1 kali MFT) yang dilakukan setiap jam pembelajaran pendidikan jasmani dan kesehatan disekolah. Pada pertemuan pertama siklus II, peneliti meningkatkan jumlah pos/stasiun latihan circuit training dengan menjadi 8 pos/stasiun latihan yang terdiri dari: Shuttle Run, Sit-Up, Squat Jump, Push-Up, Lompat Cone, BackUp, Squat Trush dan Static Lunge. Sama halnya dengan pertemuan pertama di siklus I, perbandingan waktu yang digunakan pada pertemuan pertama di siklus II ini adalah 30:60 detik atau 30 detik melakukan gerakan dalam setiap pos dan 60 detik istirahat sembari mempersiapkan untuk aktivitas circuit training di pos selanjutnya.

Pada pertemuan kedua siklus II, peneliti masih menggunakan latihan circuit training dengan 8 pos/stasiun latihan yang terdiri dari: Shuttle Run, SitUp, Squat Jump, Push-Up, Lompat Cone, Back-Up, Squat Trush dan Static Lunge. Namun pada pertemuan kedua siklus II ini selain menggunakan 8 pos/stasiun latihan, peneliti meningkatkan waktu yang digunakan menjadi 60:60 detik atau 60 detik melakukan gerakan dalam setiap pos dan 60 detik istirahat sembari mempersiapkan untuk aktivitas circuit training di pos selanjutnya dengan tujuan untuk mendapatkan hasil yang lebih baik lagi. Pada pertemuan kedua siklus II, untuk yang kedua kalinya peneliti menggunakan lembar observasi aktivitas guru dan siswa yang diamati oleh guru pamong pak Febridian dan teman sejawat Ade Andri Setiawan. Pada lembar observasi guru, peneliti mendapatkan nilai 93,33\% untuk nilai mengajar menjadi guru dan $86,66 \%$ untuk nilai observasi aktivitas siswa dalam pembelajaran.

Pada pertemuan ketiga siklus II merupakan pertemuan akhir dari siklus II, peneliti menggunakan Multistage Fitnes Test (MFT) untuk mengukur kembali kemampuan $\mathrm{VO}_{2}$ Max siswa kelas VIII.4 SMP Negeri 4 Kota Bengkulu setelah diberikannya lagi tindakan selama satu siklus. Dari Multistage Fitnes Test yang telah dilaksanakan ternyata kemampuan $\mathrm{VO}_{2}$ Max siswa mengalami peningkatan dengan rincian: Baik Sekali 2,86\%, Baik $25,71 \%$, Sedang $51,43 \%$, Kurang $17,14 \%$ dan Kurang Sekali 2,86\%. Berdasarkan data tersebut siswa yang mendapatkan kategori sedang keatas yaitu $80 \%$ dari jumlah keseluruhan siswa kelas VIII.4 SMP Negeri 4 Kota Bengkulu dengan nilai ratarata keseluruhan $\mathrm{VO}_{2}$ Max sebesar 38.03 sehingga berkategori Sedang. Hasil dari siklus II ini sudah semakin membaik dan telah mencapai indikator keberhasilan yaitu $\geq 75 \%$, maka penelitian ini dicukupkan pada siklus II.

\section{PENUTUP}

\section{Simpulan}

Berdasarkan penelitian dan hasil analisis yang telah dilakukan tentang Peningkatan $\mathrm{VO}_{2}$ Max Melalui Latihan Circuit Training Dalam Pembelajaran Pendidikan Jasmani Pada Siswa Kelas VIII.4 SMP 4 Negeri Kota Bengkulu diperoleh kesimpulan sebagai berikut:

1. Kemampuan guru semakin baik sehingga mampu menguasai kelas dan siswa semakin tertib serta mulai bersungguh-sungguh dalam mengikuti pembelajaran. Aktivitas guru dan siswa dapat dilihat menggunakan lembar observasi guru dan lembar observasi siswa yang digunakan pada pertemuan kedua setiap satu siklus. Pada siklus I didapatkan hasil kemampuan guru adalah $80 \%$ dan nilai aktivitas siswa 
adalah 73,33\%. Pada siklus II didapatkan hasil kemampuan guru adalah 93,33\% dan nilai aktivitas siswa adalah 86,66\%. Dari hasil tersebut menunjukan bahwa setiap siklus kemampuan guru mengajar dan mengkondisikan kelas meningkat dan semakin membaik.

2. Penggunaan latihan circuit training dalam pembelajaran pendidikan jasmani dapat meningkatkan $\mathrm{VO}_{2} \mathrm{Max}$ siswa kelas VIII.4 SMP Negeri 4 Kota Bengkulu, dengan rincian: pada saat Pra-siklus diperoleh nilai yang kriteria sedang ke atas yaitu 22,86\%. Pada siklus I presentase yang mencapai kategori sedang ke atas adalah $54,29 \%$ dengan rincian $20 \%$ siswa berkriteria Baik, 34,29\% siswa berkriteria Sedang, 37,14\% siswa berkriteria Kurang, dan 8,57\% siswa berkriteria Kurang Sekali. Pada siklus II presentase yang mencapai kategori sedang ke atas adalah adalah $80 \%$ dengan rincian $2,86 \%$ siswa berkriteria Sangat Baik, 25,71\% siswa berkriteria Baik, 51,43\% siswa berkriteria Sedang, 17,14\% siswa berkriteria Kurang, dan 2,86\% siswa berkriteria Kurang Sekali.

3. Kemampuan $\mathrm{VO}_{2}$ Max siswa kelas VIII.4 SMP Negeri 4 Kota Bengkulu setelah diberi tindakan kelas yaitu dengan latihan cicuit training mengalami peningkatan dengan nilai rata-rata keseluruhan $\mathrm{VO}_{2} \mathrm{Max}$ sebesar: Pra-Siklus 27.38 dengan kategori Kurang Sekali, Siklus I 36.34 dengan kategori Sedang dan pada Siklus II 38.03 dengan kategori Sedang.

\section{Saran}

Berdasarkan kesimpulan diatas, maka dengan ini peneliti memberikan saran sebagai berikut:
1. Agar para guru olahraga dapat mengaplikasikan pembelajaran dengan menggunakan latihan circuit training untuk meningkatkan kemampuan $\mathrm{VO}_{2} \mathrm{Max}$.

2. Selain untuk meningkatkan kemampuan $\mathrm{VO}_{2} \mathrm{Max}$, latihan circuit training juga direkomendasikan untuk membantu guru dalam mengajar siswa karena latihan circuit training dapat memperbaiki secara serempak fitnes keseluruhan dari tubuh yaitu komponen power, daya tahan, kecepatan, mobilitas dan komponen fiisk lainnya serta tidak memerlukan alat yang mahal.

3. Hasil penelitian ini dapat digunakan sebagai acuan pengembangan pada penelitian berikutnya dengan menggunakan metode yang sama dan materi yang berbeda.

\section{DAFTAR PUSTAKA}

Giri Wiarto. 2015. Inovasi Pembelajaran Dalam Pendidikan Jasmani. Yogyakarta: Laksitas.

Giri Wiarto. 2015. Panduan Berolahraga untuk Kesehatan dan Kebugaran. Yogyakarta: Graha Ilmu.

Muhammad Sajoto. 1988. Pembinaan Kondisi Fisik Dalam Olahraga. Jakarta: Departemen Pendidikan dan Kebudayaan Direktorat Jendral Pendidikan Tinggi Proyek Pengembangan Lembaga Pendidikan Tenaga Kependidikan.

Pate, Rotella \& Clenaghan, M.C. (1993). Dasar-Dasar Ilmiah Kepelatihan, (Alih Bahasa: Kasiyo Dwijowinoto). Semarang: IKIP Semarang Press.

Tangkudung, James. (2012). Kepelatihan Olahraga Pembinaan Prestasi Olahraga. Jakarta: Cerdas jaya . 

,(2016).Macam-macam

Metodologi Penelitian. Jakarta: Lensa Media Pustaka Indonesia.

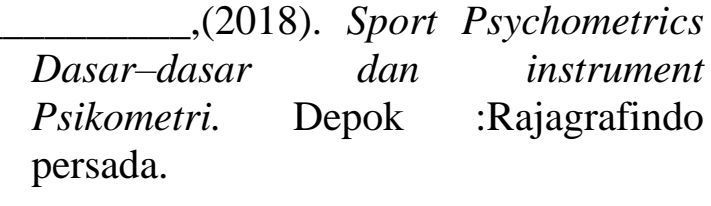

Toho Cholik Mutohir dan Ali Maksum. 2007. Sport Development index: Konsep, Metodelogi dan Aplikasi. Jakarta: PT INDEKS.

Trianto. 2011. Panduan Lengkap Penelitian Tindakan Kelas (Classroom Action Research). Jakarta: Prestasi Pustakarya. 